\title{
¿Libertad o seguridad?
}

\author{
Freedom or security?
}

\author{
Lucía Rufei Villalta Álvarez \\ Alumna del Colegio San José - Estepona (España)
}

\section{RESUMEN}

La tensión entre libertad y seguridad, entre los deseos del colectivo frente a los del propio individuo, ha estado vigente desde el nacimiento de las sociedades humanas. Dos elementos antagónicos que se complementan, desde el ámbito político hasta en la psique, dicha lucha de contrarios es constante y difícilmente podemos desligarnos de esta. La seguridad nace del deseo de salvaguardar la libertad; por lo que, al fin y al cabo, se acaba autolimitado a ella misma, paradójicamente. El ser humano ha requerido del surgimiento de la segunda para poder combatir a los de su propia especie. La combinación de ambas categorías es la clave del éxito.

\section{PALABRAS CLAVE LIBERTAD, SEGURIDAD, DIALÉCTICA HEGELIANA, SARTRE, FREUD}

\begin{abstract}
The tension between freedom and security, between the wishes of the group against those of the individual, has been in force since the birth of human societies. Two antagonistic elements that complement each other, from the political sphere to our psyche, this struggle of opposites is constant, and we can hardly detach ourselves from it. Security is born from the desire to safeguard freedom so in the end, it ends up being self-limited, paradoxically. The human being has required
\end{abstract}

1 Este trabajo ha sido seleccionado por un grupo de especialistas de entre los trabajos presentados a la VIII Olimpiada de Filosofía de Málaga organizada por FICUM en 2021. Como todos los trabajos publicados en esta revista, ha pasado por el correspondiente proceso de revisión por pares externos. De este modo, Claridades. Revista de Filosofía pretende contribuir al fomento de la filosofía entre los/as jóvenes de Málaga.

Claridades. Revista de filosofía 13/2 (2021), pp. 269-277.

ISSN: 1889-6855 ISSN-e: 1989-3787 DL.: PM 1131-2009

Asociación para la promoción de la Filosofía y la Cultura en Málaga (FICUM) 
the emergence of the latter to be able to fight his own species. The combination of both categories is the key to success.

\section{KEYWORDS}

FREEDOM. SECURITY, HEGEL'S DIALECTICS, SARTE, FREUD

DesDe los PRINCIPIOS DEL PENSAMIENTO humano, del desarrollo de las sociedades e incluso de la mismísima naturaleza, una de las leyes dialécticas que ha regido esta progresión ha sido la lucha de contrarios. No podemos hablar de desarrollo sin apelar a las contradicciones y la superación de estas.

La realidad es un ciclo caduco, en la que constantemente se da una lucha entre lo que nace y lo que desaparece, entre lo que florece y lo que muere. Haciendo una distinción entre la metafísica y la dialéctica, la segunda considera que todos los entes llevan implícitos contradicciones propias e internas, pues al fin y al cabo todos poseen un lado positivo y negativo, un pasado y un futuro, su lado caduco y su lado progresivo... Por este motivo, la dialéctica entiende el desarrollo no como un proceso armónico entre fenómenos, sino como la confrontación de opuestos y contradicciones.

Las contradicciones internas reflejan que todo ente posee aspectos que se hallan ligados entre sí, pero que a su vez se excluyen mutuamente, y se niegan. Inseparables pero opuestos, dentro de un todo. Si en matemáticas es el + y el -, o en mecánica, acción y reacción, como recuerda Lenin, en la ciencia social es la lucha de clases. Pues bien, en cuestión de derechos humanos, es libertad o seguridad.

Lo antagónico se complementa, pero a la vez se anula mutuamente. ¿Qué ocurre si no se puede hallar un equilibrio? Por mucho que sean complementarios si $\mathrm{A}$ es tres veces mayor que $\mathrm{B}$, ¿acaso una no acaba inhibiendo una a la otra?

Este debate entre libertad y seguridad surge como consecuencia del origen de las civilizaciones y comunidades humanas. Un debate de mayor envergadura engloba al tema de esta disertación ya que todo parte de los intereses colectivos frente a los intereses del propio individuo, las necesidades de la sociedad contra las del ser. De este modo, la problemática se expande y toma tonos mucho más profundos y trascendentales en los que no entraremos. 
Poder cohonestar ambas categorías, la libertad y la seguridad, es un reto. El contexto que nos envuelve es multipolar, asimétrico, cargado de amenazas emergentes y riesgos. El deber de cualquier estado de gobierno y a menor escala, de cualquier individuo, es la autoprotección.

Desde el terrorismo internacional, hasta los mayores deseos que gobiernan nuestro subconsciente representan un riesgo contra el que debemos de lidiar. Por ello se establecen tres tipos de prohibiciones que nos mantienen a salvo. Las del Estado, tanto leyes como reglas; las que propone la sociedad, que sanciona desde el ámbito público y; finalmente, las de la propia persona que nos limitan.

Decía Sartre que el hombre está condenado a ser libre. Esta célebre frase nos describe perfectamente la relación que tiene la libertad con el ser humano; es decir, esta es inherente al mismo; por ello este se debe responsabilizar de todo lo que haga con ella. Todos vivimos la libertad, pero cada quién con sus particularidades. El hombre se encuentra atado a sus decisiones y mediante sus acciones se encarga de ir encaminando su vida. Esta libertad de decisión puede resultar tediosa como bien se nos ejemplifica en la versión apócrifa de La Odisea de Lion Feuchtwanger. O incluso puede asfixiarnos tal como le sucede a Meursault en la obra de Albert Camus.

Es imposible desligarse ya que el único factor limitante es ella misma. La libertad se autolimita, aunque esto pueda sonar paradójico. La seguridad es un producto de la sociedad que tiene como fin la protección del conjunto. Así se consigue resguardar y preservar el desarrollo de la libertad, pues para que exista la libertad se tiene que complementar con las prohibiciones; para que ésta cobre sentido alguno.

Siguiendo esta lógica, en un Estado de Derecho el gobierno posee la potestad de condenar al individuo si representa una amenaza para la sociedad, ha incumplido la Constitución o demás actos considerados delictivos. La seguridad de todos predomina ante la individualidad en el momento en el que el sujeto se salga del margen legal establecido. Cabe remarcar que las leyes tienen como fin velar por los ciudadanos y requieren estar adaptadas a las necesidades de la época siendo igualitarias y justas. 
Resumiendo, cuando la libertad personal solapa con algo más grande que el individuo, es decir, con la sociedad, esta pierde la batalla por la regla del más fuerte. Así se nos demuestra que la libertad tiene límites: mi libertad termina donde comienza la de los demás.

$\mathrm{Y}$ aquí es donde se comete el error y por ello se abre esta disertación. Cuando el poder ciega y provoca el alejamiento del verdadero motivo de la existencia de esta ley esencial para la vida en comunidad. Cuando por defecto se asocia seguridad a privación, en el sentido negativo del término, debido a que es lo que estamos acostumbrados a vivir. Cuando damos por hecho elementos que no son tan claros. Procederé a ejemplificarlo.

El terrorismo ha provocado bastantes estragos, por ende, los distintos gobiernos han desarrollado protocolos para detener a las bandas de captación exprés y tráfico de personas. Estos captores se valen de la dialéctica y la retórica, tal y como hacían los sofistas, y embaucan a la gente. Sofismas, falacias, engaños mediante argumentos... captan a individuos y los alienan en su totalidad.

Un caso que cabe destacar es el de María Ángeles, la cual era una chica andaluza entre cuyas aficiones destacaba el rock. Aún pueda parecer extraño, de la noche a la mañana, decidió cambiar la guitarra por el velo y se convirtió al islamismo.

Todos somos independientes de decidir nuestra religión, sin embargo, el problema surge cuando el principal motivo de esta fe no es por incentivo propio, sino que es fruto de la persuasión. A esta chica la encandilaron con dulces palabras y falsas promesas, bajo la sombra del amor se escondía un propósito más oscuro y siniestro.

El amor pasó a ser obsesión, y al final desembocó en una vocación inaudita. Estas bandas captoras de mujeres se esconden tras perfiles falsos prometiéndoles el cielo y ellas se ven sobrecogidas. Lo que pudo empezar por pura curiosidad, poco a poco se fue incrustando en el cerebro de María y acabó convirtiéndola en un ser totalmente alienado.

Su cerebro fue vilmente ensombrecido por mano de tácticas inéditas hasta el surgimiento de la era digital. Es como si un pequeño demonio se hubiese escondido tras su oreja y fuera susurrándole cómo debía pensar y actuar, y ante la poca fortaleza mental que poseía se dejó embaucar y controlar. 
Nadie lo vio venir, nadie se lo esperaba, porque todo fue exclusivamente tras una pantalla. Compró un billete de ida, pero no de vuelta, fue interceptada por la policía, ¿salvación o privación de la libertad? La respuesta depende de los ojos con los que mires, pero, sin lugar a duda, ella se dejó caer en un pozo sin fondo en el momento en el que el ratón hizo clic. ¿¿Se hizo lo correcto?

Lo anteriormente mencionado se puede extrapolar al caso de las mujeres que portan velos. En muchas ocasiones los individuos de los países primermundistas occidentales vemos este acto como símbolo de opresión, sin embargo, intentando «liberarlas» y protegerlas de su «infame» cultura acabamos privándolas de su libertad de elegir. Es justificado con un fundamento de dudosa veracidad, "están alienadas, no es voluntad sino la presión de la comunidad y la costumbre», dirán muchos. Aquí la cuestión: ¿son acaso los países más desarrollados los principales segadores de libertad para aquellos que no entren dentro de sus principios?

Por lo que observamos estos países son los que plantean esta pregunta ¿libertad o seguridad?, porque irónicamente ya poseen ambas y desean ampliarlas. No obstante, si vamos a Siria, por ejemplo, las respuestas que obtendremos serán completamente diferentes sin lugar a duda. Preferirán la seguridad, el fin de la guerra, y ya después cabrá la posibilidad de hablar de libertades y derechos. Porque sin una base en la que te puedas resguardar es imposible desarrollarte plenamente como individuo independiente. Pues como parece que dijo Samuel Johnson en el siglo XVIII: la libertad, por lo que respecta a las clases sociales inferiores de cada país, es poco más que la elección entre trabajar o morirse de hambre.

Otros gobiernos han maquillado un control totalitario de las libertades de sus ciudadanos como si se tratara de seguridad. En China, como bien hemos visto, el coronavirus ha sido confrontado mediante las extremas medidas impuestas que han sido altamente efectivas. Dichas normas han podido ser tan restrictivas debido al sistema por el que se rige el gobierno, remarcando, nos encontramos en una situación límite y por ello requiere de soluciones drásticas, pero tristemente ese es el día a día de la comunidad china, viven bajo esa presión gubernamental que los anula. 
Entonces, en cuestiones gubernamentales no se puede establecer una uniformidad definida entre ambas necesidades, sino que dependiendo del estado del país y de los requerimientos de la población se debe optar por el mejor balance.

El debate entre seguridad y libertad se ve también reflejado dentro de la propia mente por lo que Sigmund Freud delimitó como el Ello y el Superyó. Nuestra libertad es poder hacer todo aquello que deseamos y dejarnos llevar por nuestros instintos y deseos. Irónicamente, aún teniendo la posibilidad de hacerlo nos auto limitamos por la sencilla y lógica razón de que, si siempre satisfaciéramos nuestras pulsiones sin filtro ni prudencia, a menudo nos enredaríamos en conflictos con el mundo externo que supondrían una amenaza para el individuo. Algo realmente contraproducente. El Superyó representaría la otra cara de la moneda; insistencia moral y el juicio social. Equilibra la balanza y contrarresta a las pretensiones. El yo sería es el mediador entre ambas e intenta satisfacer las necesidades del Ello a la vez que concilia las exigencias del Superyó, se encarga de la autoconservación y de la seguridad individual. Tiene que lidiar a dos bandas, con los peligros que acarrea el mundo exterior y con la demanda del escenario intramental.

Ese proceso conocido como «madurar» quizás no sea más que la aparición de las cadenas que nos limitan y nos hacen conscientes de que por nuestro bien hemos de actuar adecuadamente. Al fin y al cabo, dejamos atrás esa juventud y sensación de inmortalidad y nos hacemos conscientes de la realidad en la que vivimos.

Incluso en lo más mínimo el propio hombre se retrae para no poner en compromiso su seguridad ni libertad. Por poner un ejemplo sencillo, imaginemos a un empleado de oficina. Su jefe no es de su agrado, él tiene la libertad de coger sus cosas e irse; pero por su bien, por su seguridad y estabilidad económica no lo hace. Esto conlleva a que siga manteniendo su nivel de vida y pueda tener el dinero necesario para llevar una vida acomodada y unas relaciones socioculturales activas. Así podemos demostrar que también existen libertades que se deben de comprar, tristemente, y que no todo el mundo tiene acceso a ellas. De alguna forma u otra estas 
dependen de nuestra seguridad en este caso económica, y en el ejemplo anterior, física, como puede ser una guerra.

Traspasando esta pequeña representación de nuestra psique al ámbito social podemos decretar que el ser humano siempre va a priorizar su seguridad por pura razón evolutiva. Como se ha mencionado con anterioridad, es contraproducente no limitar la libertad si esta te acaba matando.

Puede parecer un poco vesánico e incluso enrevesado la relación que encuentro entre esta disertación y el relato corto escrito por Ursula K. Le Guin conocido como Los que se alejan de Omelas. A mi parecer es un muy buen ejemplo para poder describir lo que representa la seguridad en esta sociedad que lucha por la libertad. Contextualizando, Omelas es una utopía máxima que depende única y exclusivamente del sufrimiento de un niño.

Todas nuestras libertades se fundamentan en el hecho de que podemos ser capaces de expresarnos sin recelo, podemos cambiar y ampliar la ley porque así nos resguarda la misma, somos capaces de todo porque estamos en un contexto que nos ampara de la intolerancia y los posibles ataques. Ahora bien, todo tiene un precio, por ello debemos dar un poco de esta libertad para mantener la estructura. Algunos que se percatan de esto se escandalizan y desean una libertad plena, egoístamente. Ese niño maltratado reside en todos y cada uno de nosotros en una pequeña proporción, esa «injusticia» que tenemos que sufrir para que a mayor escala disfrutemos de todo tipo de lujos y que mantiene todo lo que hoy en día conocemos. Aquellos que no están dispuestos a mantener a ese niño interior en la oscuridad se alejan de Omelas, se alejan de la sociedad, se dirigen a un lugar inimaginable hoy en día, pues al no ceder esa parte de sí boicotean a sus iguales y acaban oprimiendo a los demás bajo el término de igualdad y seguridad por una sociedad libre.

Si nos planteamos el caso hipotético de que todos los seres humanos fuéramos plenamente empáticos, no violentos, generosos... si idealizamos al hombre en su plenitud, claramente la libertad no dependería de la seguridad pues no temeríamos a que la primera se viera limitada por ningún ente ni institución. 
Pero no es el caso, debemos tener en cuenta que somos egoístas y la situación de Omelas es un puro reflejo de la sociedad, desde tiempos inmemoriales los poderosos se han valido de los más indefensos y pobres para mantener su nivel de vida. Amos y esclavos, señores y campesinos, jefes y obreros... son la representación de la ciudad utópica que se vale de los desfavorecidos y que hasta bien entrado el siglo XXI no se ha intentado remediar. Aún dudo de que este sistema no siga en pie, pero no vamos a entrar en este debate. Sí, respondiendo a la pregunta planteada anteriormente, los países primermundistas han sesgado las libertades de aquellos que no pertenecen a su «estamento» y lo siguen haciendo.

Por ello, como somos egoístas e individualistas deseamos mantener nuestra libertad y que sean los demás los que den la suya. Por este motivo, aún no se ha encontrado un modelo económico de consenso, por ese motivo no se han establecido las leyes que resguarden todas las libertades, por este motivo, y perdonen la insistencia, aún hay países que no pueden hablar de libertad, por este motivo aún existe este debate.

Este tópico no debería ni de cuestionarse, la libertad es innata y la seguridad no es un privilegio. Como bien se expresó al comienzo de la disertación, y apelando a la dialéctica hegeliana; la tesis y la antítesis, la libertad y la seguridad se funden en la síntesis superando la contradicción y resultando una armonización de ambas.

Tanto en el ámbito social como en el personal dicha síntesis no es equitativa, ya que cada quien tiene unas necesidades diferentes que van a inclinar la balanza más hacia un lado que hacia el otro. Si A es tres veces mayor que B no la inhibe pues, esta situación se mantendrá hasta que se alcance el punto de equilibrio entre ambas magnitudes.

En conclusión, tras analizar todos los puntos planteados a lo largo del desarrollo del ensayo he podido llegar a las siguientes conclusiones:

- No se trata de elegir una u otra sino que su combinación es la clave de que ambas prevalezcan.

- La lucha entre seguridad y libertad se puede contemplar como una asociación simbiótica que permite el desarrollo mutuo.

- El ser humano, por naturaleza es egoísta y ha provocado que la seguridad tenga que salvaguardar a la libertad. Es primordial para que 
cualquier ser se desarrolle en su plenitud y por consecuente pueda expresar su libertad.

Como broche de la disertación me gustaría apelar a Cicerón y su célebre enunciado que sintetiza a la perfección las ideas desarrolladas durante todo el discurso: para ser libres, hay que ser esclavos de la ley. 
